Fertil Steril. 2014 April ; 101(4): 1047-1054.e5. doi:10.1016/j.fertnstert.2013.12.041.

\title{
Association of physical activity in the past year and immediately after in vitro fertilization on pregnancy
}

Kelly R. Evenson, Ph.D., M.S. ${ }^{a}$, Kathryn C. Calhoun, M.D.d,e, Amy H. Herring, Sc.D. b,c, David Pritchard, M.S. ${ }^{c}$, Fang Wen, M.S., M.Sc. ${ }^{a}$, and Anne Z. Steiner, M.D., M.P.H. ${ }^{d}$

aDepartment of Epidemiology, University of North Carolina, Chapel Hill, North Carolina

${ }^{b}$ Carolina Population Center, University of North Carolina, Chapel Hill, North Carolina

'Department of Biostatistics, Gillings School of Global Public Health, University of North Carolina, Chapel Hill, North Carolina

dDepartment of Obstetrics and Gynecology, School of Medicine, University of North Carolina, Chapel Hill, North Carolina

${ }^{\mathrm{e} A t l a n t a}$ Center for Reproductive Medicine, Atlanta, Georgia

\begin{abstract}
Objective-To estimate the association of physical activity on in vitro fertilization (IVF).

Design-Prospective cohort study.

Setting-Academic infertility clinic.

Patient(s)-Women ( $\mathrm{n}=121$ ) undergoing nondonor IVF embryo transfer (fresh or frozen).

Intervention(s)-The women completed a questionnaire on past year physical activity and wore an accelerometer from embryo transfer to serum pregnancy testing.

Main Outcome Measure(s)-Implantation, intrauterine gestation, and live birth.

Result(s) - Based on self-reported past year physical activity, the adjusted odds of intrauterine gestation was higher among those that had higher continuous active living (odds ratio [OR] 1.96, 95\% confidence interval [CI] 1.09-3.50), sports/exercise (OR 1.48, CI 1.02-2.15), and total activity (OR 1.52, 95\% CI 1.15-2.01) indices. After embryo transfer, women did almost no vigorous activity (median $0 \mathrm{~min} / \mathrm{d}$ ) as measured by the accelerometer. More of their time was spent in light activity (median $3.0 \mathrm{~h} / \mathrm{d}$ ) and sedentary behaviors (median $9.3 \mathrm{~h} / \mathrm{d}$ ). Accelerometermeasured physical activity and sedentary behavior after embryo transfer were not associated with any IVF outcome.
\end{abstract}

Copyright $\odot 2014$ American Society for Reproductive Medicine, Published by Elsevier

Reprint requests: Kelly R. Evenson, Ph.D., 137 East Franklin Street, Suite 306, Department of Epidemiology, Gillings School of Global Public Health, University of North Carolina, Chapel Hill, NC 27514, kelly_evenson@unc.edu.

Use your smartphone to scan this QR code and connect to the discussion forum for this article now.*

Discuss: You can discuss this article with its authors and with other ASRM members at http://fertstertforum.com/evensonk-physicalactivity-ivf-pregnancy-implantation/

K.R.E. has nothing to disclose. K.C.C. has nothing to disclose. A.H.H. has nothing to disclose. D.P. has nothing to disclose. F.W. has nothing to disclose. A.Z.S. reports consulting with Roche Diagnostics in 2011.

Interim data presented by Kathryn C. Calhoun, M.D., at the American Society for Reproductive Medicine conference, October 20-24, 2012, San Diego, California. 
Conclusion(s)-An active lifestyle in the preceding year favorably impacted the IVF outcome. After embryo transfer, women engaged in mostly light physical activity and sedentary behaviors; therefore, the impact of vigorous physical activity on implantation could not be determined.

\section{Keywords}

Accelerometry; conception; implantation; pregnancy; questionnaire; sedentary behavior

Physical activity appears to be beneficial during pregnancy. Research shows reduced risks of gestational diabetes and preeclampsia and a shorter length of labor without adversely impacting the baby (1-3). The American Congress of Obstetricians and Gynecologists recommends that in the absence of any contraindications, pregnant women should engage in moderate intensity exercise for at least 30 minutes on most, if not all, days of the week (4). There are no definitive physical activity guidelines for women attempting conception, particularly for the window of implantation and luteal phase. The window of implantation is difficult to pinpoint except during in vitro fertilization (IVF) cycles.

Moderate activity can increase insulin sensitivity, reducing carbohydrate-induced hyperinsulinemia (5). This may be beneficial to implantation, as hyper-insulinemia is associated with reduced levels of glycodelin and insulin-like growth factor-binding protein 1 , which appear to facilitate adhesion at the maternal-fetal interface during implantation $(6$, 7). However, vigorous activity lowers leptin levels (5). Leptin appears to be important in regulating embryo implantation and endometrial receptivity by promoting blastocyst adhesion and blastocyst outgrowth on fibronectin and by stimulating trophoblast invasion $(8$, 9).

Biologic evidence supports a hypothesis that physical activity affects implantation, and several epidemiologic studies indicate an association between self-reported frequent vigorous activity and fertility (10-12). A study of 2,232 infertile women undergoing IVF found that those who reported exercising $\geq 4$ hours/week for the past $1-9$ years were less likely to conceive and have a live birth than women without a history of exercising (13). Because that study did not examine physical activity during the implantation window, it is unclear if failed implantation was due to physical activity occurring close to implantation or physical activity occurring in the past.

The present prospective cohort study focused on an IVF population and explored associations between past year and current physical activity and implantation success, clinical intrauterine gestation, and live birth following IVF. We chose an IVF population for three reasons: The implantation window could be targeted, it provided greater statistical power due to higher fecundability than in the general population, and it shortened the follow-up interval. Past year physical activity was assessed with the use of a self-reported questionnaire. Unique to this study was collection of physical activity with the use of accelerometry after IVF, allowing precise assessment during the implantation period.

\section{MATERIALS AND METHODS}

\section{Study Population}

This study was reviewed and approved by the Institutional Review Board at the University of North Carolina-Chapel Hill (UNC). During 2010-2012, women receiving fresh or frozen embryo transfer after IVF at the UNC Reproductive Endocrinology and Infertility Clinic were recruited by their physician and enrolled after providing written informed consent. Eligible participants were ambulatory (a requirement for accelerometer measurement), English speaking, and literate. Recipients of donor oocytes and previous study participants 
were ineligible. Before embryo transfer, women completed a questionnaire on physical activity, reproductive and general health, and sociodemographics. On embryo transfer day, women were given an accelerometer to wear and a diary to keep, both until their scheduled serum pregnancy test. For all women, no restrictions were placed on physical activity except to limit physical activity on transfer day.

\section{Outcome Assessment}

In general, fresh embryo transfers were done on day 3. Day 2 embryo transfers were generally offered to women with few fertilized embryos on day 1 . Frozen embryos tended to be blastocysts (day 5 or day 6). The primary outcomes were: 1 ) the result of a serum pregnancy test $(\beta$-hCG $>5 \mathrm{mlU} / \mathrm{mL}$ considered to be positive) conducted on embryo day 14 , referred to as implantation; 2) clinical intrauterine gestation, defined as presence of at least one intrauterine gestational sac on ultrasound; and 3) live birth as abstracted from medical records.

\section{Self-reported Physical Activity}

The questionnaire included the modified Kaiser Physical Activity Survey (14), created from the original Baecke questionnaire (15). Based on a comprehensive review, it is one of the few physical activity questionnaires with evidence for both validity and reliability among pregnant women (16). The questionnaire assessed physical activity in the past year from four domains, each ranging from 1 (least active) to 5 (most active). In all cases, component questions indicating less activity were reverse coded. A total activity index was derived from the four domains. Earlier studies indicate that the total activity index has acceptable validity (0.49-0.59 Spearman correlation coefficient with accelerometry) and 1-week testretest reliability (0.84 intraclass correlation coefficient) (17).

1. The household/caregiving index included 11 items on child and elder care, meal preparation, cleaning, home repair, shopping, gardening, and outdoor work.

2. The occupational index included a screening question, asking whether the participant worked, and seven work-related items on sitting, standing, walking, lifting heavy loads, sweating from exertion, being tired after work, and comparison to others their own age regarding their work. Women who did not work were assigned a value of 1 .

3. The active living index included four items on walking, bicycling, active transportation, and television/video watching.

4. The sports/exercise index included three global 5-level questions on playing sports/ exercise, sweating during sports/exercise, and assessing recreational activity compared with others their own age. Each of the three questions contributed onefourth of the score. The final one-fourth of the score, the "sports score," was composed of nine items on the three most frequent sports/exercises in which the women engaged in during the past year. Time for each activity was assessed in hours/week and rescaled as follows: $<1$ hour/week (0.04), 1 to $<2$ hours/week (0.17), 2 to $<3$ hours/week (0.42), 3 to $<4$ hours/week (0.67), and $\geq 4$ hours/week (0.92). Duration for each activity was assessed in number of months per year and rescaled as follows: <1 month (0.5), 1-3 months (1.3), 4-6 months (2.5), 7-9 months (3.5), and 10-12 months (4.5). Absolute intensity was assessed in metabolic unit (MET) values that were assigned from the Compendium of Physical Activities (18). The MET values were rescaled as follows: <4 METs (0.76), 4-6 METs (1.26), and $>6$ METs (1.76). The rescaled (time $\times$ duration $\times$ METS) were summed over the three activities. Sports scores were rescaled as follows: 0 (1), 0.01 to $<4$ (2), 4 to $<8$ (3), 8 to $<12$ (4), and $\geq 12$ (5). Participants not engaging in sports/ 
exercise in the past month were assigned a value of 1 . The sports/exercise index was calculated by adding together the three global questions and the sports score, then dividing the sum by 4 .

A total activity index was calculated by adding the four indices, each of which contributed equally to the final score: [(household/caregiving index $\times 0.25)+$ (occupational index $\times$ $0.25)+($ active living index $\times 0.25)+($ sports/exercise index $\times 0.25)] \times 4$. Theoretically, scores could range from 4 to 20 .

\section{Accelerometer Assessment}

To obtain an objective measure of physical activity after embryo transfer, women wore an Actigraph (model GT1M) accelerometer secured on their right hip by a belt to measure acceleration in the vertical plane multiple times within a given frequency. These counts were summarized over a prespecified time period or epoch (30 seconds). Women were asked to remove the accelerometer only when sleeping, showering, or engaging in water activities. In conjunction with the accelerometer, women kept a daily diary to capture water activities that would be missed by the accelerometer. The accelerometer started collecting data the day after the IVF procedure (starting at midnight). Women were asked to wear the accelerometer until their scheduled pregnancy test. All accelerometer analyses were based on embryo day of development and not the day of transfer. Embryo transfers occurred between embryo day 2 and 5. Therefore, accelerometer data were retained starting at embryo days 6 through 13 .

Nonwear was determined with the use of the Choi algorithm (19), defined as at least 90 consecutive minutes of zero counts, with allowance of up to 2 minutes of nonzero counts if no counts were detected in a 30-minute window upstream and downstream of the 90-minute period. Counts for nonwear minutes were set to missing. A compliant day for inclusion was defined as $\geq 8$ hours of wear time. To be included in the analysis, each participant needed to contribute at least 3 days of accelerometer data from embryo days 6 to 13 .

Physical activity was calculated as average counts per 30 seconds and converted to minutes per day based on time spent in different physical activity intensities. Intensity cutoff points were similar to those used in the National Health and Nutrition Examination Survey for 1minute epochs, divided in half $(20,21)$. Vigorous intensity was defined as 23,000 counts per 30 seconds and moderate intensity as 1,010-2,999 counts per 30 seconds. A lower moderate intensity threshold was calculated based on studies that incorporated more lifestyle activities, defined as 380-1,009 counts per 30 seconds (22). Light intensity was defined as $50-379$ counts per 30 seconds and sedentary behavior as $<50$ counts per 30 seconds.

\section{Other Measures}

A self-administered questionnaire was completed before embryo transfer to avoid issues regarding recall bias due to success or failure to become pregnant. It included items on sociodemographics (age, education, race/ethnicity, and marital status), cigarette smoking, alcohol use, weight, height, and pregnancy history. From the medical record, we abstracted weight, height, parity, earlier IVF cycles, embryo information (day, type, and number transferred), and birth outcomes. Body mass index (BMI) was defined as weight in kilograms divided by height in meters squared and categorized as underweight $(<18.5 \mathrm{~kg} /$ $\mathrm{m}^{2}$ ), normal weight $\left(18.5\right.$ to $\left.<25 \mathrm{~kg} / \mathrm{m}^{2}\right)$, overweight $\left(25\right.$ to $<30 \mathrm{~kg} / \mathrm{m}^{2}$ ), or obese ( $230 \mathrm{~kg}$ / $\mathrm{m}^{2}$ ).

\section{Sample and Statistical Analyses}

In total, 133 women seeking IVF signed the consent form and enrolled in the study. Nine were missing embryo transfer information because of procedure cancellation and three did 
not complete either the questionnaire or wearing the accelerometer, leaving an analysis sample size of 121. Among the 121 included women receiving an embryo transfer, three did not complete the questionnaire, leaving 118 for analyses of self-reported past year physical activity. Among the 121 included women receiving an embryo transfer, 13 did not wear the accelerometer and 12 did not wear the accelerometer enough to be compliant, leaving 96 for analyses of accelerometry.

First, we conducted descriptive analyses of the sample, including characterizing selfreported past year physical activity and the variation in physical activity from the accelerometer. A Spearman correlation coefficient was used to compared the total activity index from the questionnaire to average total counts per 30 seconds from the accelerometer.

Wilcoxon-Mann-Whitney nonparametric tests were used to compare whether physical activity differed by pregnancy outcome. Unconditional logistic regression characterized the association between physical activity and pregnancy outcomes. A priori, we retained both age and BMI in all models owing to their association in the literature with both physical activity and birth outcomes, although we found that they generally did not confound the associations. For all accelerometer models, we also included average time per day of accelerometer use. Potential confounders (education, race/ethnicity, smoking, parity, previous pregnancy, previous IVF, type of embryo transfer [fresh or frozen]) were considered if they were associated with both physical activity and any of the pregnancyrelated outcomes. For all of these variables, none changed the odds ratio between physical activity and the outcome by more than $10 \%$. Because they failed to meet the definition of confounding, they were dropped from all final models.

For all models, we explored physical activity both continuously and categorically (split at the median). For the past year physical activity indices, we tested whether the addition of a quadratic physical activity term was needed in the model. In all cases, the quadratic terms were dropped, because they did not contribute when assessed with the use of likelihood ratio tests $(P<.05)$. These analyses were conducted with the use of SAS 9.3. We also considered Bayesian time-varying coefficient logistic regression models to further explore relationships between each of the accelerometer measured physical activity measures during days 6-13 of embryo development and the three IVF outcomes. The model and software used are explained in greater detail in Appendix 1 (available online at www.fertstert.org).

\section{RESULTS}

\section{Sample Description}

The sample was highly educated and predominantly White (Table 1). More than one-half were normal weight, and none were currently smoking. Overall, $58.1 \%$ had been pregnant in the past, with $30.6 \%$ reporting a parity of at least 1 . Among 68 women who had been pregnant in the past, 36 had undergone fresh assisted and 19 frozen assisted reproductive cycles. In the current cycle, most women (82.6\%) received a fresh embryo transfer. Among the 121 women receiving IVF, $51.2 \%$ resulted in implantation, $38.8 \%$ in clinical intrauterine gestation, and $26.5 \%$ in live birth. All characteristics presented in Table 1 were calculated separately for those that provided compliant accelerometry $(n=96)$ and those that completed the questionnaire $(n=118)$. No category presented in Table 1 differed by more than $5 \%$ when comparing either subsample with the full sample ( $\mathrm{n}=121$; data not shown).

\section{Physical Activity of the Sample}

Of the four indices on past year physical activity, sports/exercise displayed the most variability (Table 2). The Spearman correlation coefficient was 0.27 (95\% confidence 
interval $0.05-0.48$ ) between the total activity index from the past year physical activity questionnaire and average total counts per 30 seconds from the accelerometer, the objective measure of physical activity after embryo transfer.

The accelerometer indicated almost no vigorous activity performed during the time from embryo transfer to the pregnancy test (median 0, interquartile range 0-0). Eight women (8.3\%) engaged in an average of $\geq 5 \mathrm{~min} / \mathrm{d}$ and 3 women (3.1\%) in an average of $\geq 10 \mathrm{~min} / \mathrm{d}$ vigorous activity. Overall, a median of $10.7 \mathrm{~min} / \mathrm{d}$ (interquartile range 6.5-11.0) were spent in moderate activity and $49.2 \mathrm{~min} / \mathrm{d}$ (interquartile range 45.0-58.0) in low moderate activity. Among the sample, 25 women (26.0\%) engaged in an average of $220 \mathrm{~min} / \mathrm{d}$ moderate activity. Most of the time was spent in light activity (median $3.0 \mathrm{~h} / \mathrm{d}$ ) and sedentary behaviors (median $9.3 \mathrm{~h} / \mathrm{d}$ ).

\section{Physical Activity and Pregnancy Outcomes}

For physical activity in the past year, those with higher total activity indices were more likely to have all three favorable pregnancy outcomes (Table 2; Supplemental Table 1 [available online at www.fertstert.org]). Those with higher median active living and sports/ exercise indices were more likely to have a clinical intrauterine gestation. These findings were supported in the adjusted models, where odds of a positive pregnancy test and clinical intrauterine gestation were generally higher among those with higher active living, sports/ exercise, and total activity indices compared with those with lower scores indicating less physical activity in the past year (Table 3). The odds ratios attenuated for the live birth outcome and findings were consistent whether physical activity was continuous or categorized at the median. There were no associations identified for household/caregiving, and only the occupational index was associated with higher odds of a live birth when categorized at the median.

Accelerometer-measured physical activity and sedentary behavior after embryo transfer were not associated with IVF outcomes when comparing medians (Table 2; Supplemental Table 1) or in adjusted logistic regression analyses (Table 4). To explore this further, we considered a Bayesian logistic regression model with autoregressive coefficients for the linear effect of physical activity and sedentary behavior measures separately for the three pregnancy outcomes. The results of the models were generally not suggestive of any consistent pattern of associations (Supplemental Figs. 1-3 [available online at www.fertster.org]).

\section{DISCUSSION}

Self-reported physical activity in the year before cycle start was associated with higher odds of implantation and clinical intrauterine gestation following IVF. However, sports and exercise did not ultimately affect the odds of live birth following IVF. Of the domains, lifestyles including more active living (walking, bicycling, active transportation, less television watching), sports, and exercise appeared to favor implantation and pregnancy. These are activities of choice, rather than activities of necessity, such as those involving household, caregiving, or work. Self-selection to engage in these particular activities can not be ruled out. The women determined whether or not they were active in the past year, owing to the observational design of the study.

The majority of women did not exhibit much moderate to vigorous activity after embryo transfer. Within the observed range, more physical activity or less sedentary behavior appeared to have no impact on implantation, intrauterine gestation, or live birth. In contrast, another study of 131 women found that implantation and pregnancy rates were higher among those with higher physical activity during the week after IVF (23). However, that 
study did not consider confounding and relied on self-reported physical activity. After IVF, our sample averaged $10.7 \mathrm{~min} / \mathrm{d}$ moderate activity as measured with accelerometry. This amount is lower than the national average of 20-22 $\mathrm{min} / \mathrm{d}$ for women 20-39 years (years 2003-04) (20), but similar to a national average of $11.5 \mathrm{~min} / \mathrm{d}$ for pregnant women during their first trimester (years 2003-06) (24), both results from studies using a similar accelerometer.

In our sample, few women engaged in vigorous activity after IVF, preventing us from adequately exploring whether higher-intensity physical activity was associated with pregnancy outcomes. Several epidemiologic studies indicate reduced fecundability among those reporting the highest-intensity exercise (11-13), whereas several other epidemiologic studies do not $(10,25,26)$.

The questionnaire on past year physical activity indicated that this sample of women seeking IVF had higher median sports/exercise (3.5) and total activity indices (10.6) than those measured similarly among a select group of postpartum women (medians 2.3 sports/exercise and 8.8 total activity) (27) and among prepregnant Latina women (median 2.0 sports/ exercise) (28). However, the distribution of scores was similar among ethnically diverse women 20-65 years of age (29). Two studies indicated that physical activity declines while women undergo IVF compared with levels before treatment $(23,30)$. In the present study, we did not readminister the questionnaire after IVF, and are unable to precisely quantify changes in specific domains of physical activity. However, when comparing self-reported past year activity with the accelerometer results, the differences indicate that participation in vigorous activity declined from the past year to the short period after IVF.

Sedentary behavior comprises time spent in periods of little or no movement while awake, such as sitting or bedrest, ranging from 1.0-1.5 METs $(31,32)$. This behavior is not equivalent to "lack of physical activity," because one can be physically active as well as accumulate large amounts of sedentary time. Sedentary behavior is challenging to self-report because it is common and interspersed throughout the day, and therefore it was not reported in earlier studies of IVF and physical activity. We found that longer time spent in sedentary behavior during embryo days 6-13 was not associated with pregnancy outcomes. Several other studies explored the impact of ambulation or shorter bedrest compared with longer bedrest immediately after embryo transfer, all of which indicated no difference in pregnancy outcomes $(30,33-37)$, except for one randomized study that found higher implantation rates for women assigned to 1 hour bedrest compared with 24 hours bedrest after IVF (38).

\section{STUDY LIMITATIONS AND STRENGTHS}

This study is subject to several limitations. First, the sample may not be generalizable, and findings should be confirmed in other more diverse samples. Women receiving IVF generally are more highly educated, have a higher household income, and are less likely to be overweight than the general population. Regarding representativeness of the clinic population, the sample under study $(\mathrm{n}=121)$ was similar to our general clinic population in terms of pregnancy success rates and age distribution (39).

Second, for a specific day to be included in the accelerometer analyses, we required $\geq 8$ hours of wear time on that day. Moreover, only women who provided $\geq 3$ days of accelerometer data during embryo days $6-13$ were included in the analyses. The median number of compliant days the accelerometer was worn was 7 (interquartile range 6-8). Among 96 women included in these analyses, 44 provided all possible days ( 8 days of compliant accelerometer data), 24 provided 7 days, 14 provided 6 days, 7 provided 5 days, 4 provided 4 days, and 3 provided 3 days. Therefore, the average time per day was calculated based on a range of days (3-8). The median number of compliant accelerometer days did not 
differ for two pregnancy outcomes ( $\beta$-hCG, live birth) but was lower for those with a clinical intrauterine gestation than for those without (median 7 vs. 8 days; $P=.06$ ). Although it is unlikely that the difference in 1 day of wearing the accelerometer meaningfully affected these results, it is not known whether the missing days were systematically different than compliant days and whether the assumption to average across days was valid. However, this approach is commonly used in accelerometry studies (40). The Bayesian regression models attempted to overcome this obstacle by implementing an imputation mechanism to account for the uncertainty of the missing data. The inferences induced by the models were, however, unchanged.

Third, the accelerometer used in the study required removal while in the water. This affected $8.3 \%$ of the sample, who recorded water activities during embryo days 6-13, confirming that average moderate to vigorous physical activity was somewhat higher than measured. This limitation should be overcome with newer waterproof accelerometers.

A strength of this study was the use of a physical activity questionnaire, with evidence of both reliability and validity, administered before IVF to avoid issues of differential recall. Another study strength was the use of accelerometry during the implantation period to carefully document physical activity, including the duration (minutes of physical activity), frequency, and intensity (sedentary, light, moderate, or vigorous). Earlier studies relied on self-reported physical activity measures owing to both cost and time; however, accelerometer assessments are substantially more precise, and a stronger more accurate dose-response relationship should be detected. Because the accelerometer provided precise minute-by-minute measurement, we used Bayesian regression models to explore potential relationships in more detail.

\title{
CONCLUSIONS
}

In this sample of women, physical activity and sedentary behavior immediately after IVF were not associated with pregnancy outcomes. However, physical activity during this time period, as determined by the accelerometer, indicated negligible vigorous activity. Therefore, it can not be determined from this study whether vigorous activity during the luteal phase impairs implantation. An active lifestyle in the preceding year was associated with higher odds of implantation and clinical intrauterine gestation following IVF. As others have indicated, a paradigm shift may be needed to focus more broadly on promoting regular physical activity before, during, and after pregnancy to improve outcomes (3).

\section{Supplementary Material}

Refer to Web version on PubMed Central for supplementary material.

\section{Acknowledgments}

The authors thank Ashley Calingo for her data collection assistance and the anonymous reviewers. They also thank Active Living Research, Robert Wood Johnson Foundation, for loaning accelerometers for this project.

\begin{abstract}
Supported by the National Center for Research Resources and the National Center for Advancing Translational Sciences, National Institutes of Health, through Grant Award Number UL1TR000083, and by a grant from the University Research Council at the University of North Carolina-Chapel Hill. The Robert Wood Johnson Foundation Active Living Research Program loaned accelerometers for this study. The content is solely the responsibility of the authors and does not necessarily represent the official views of the National Center for Research Resources, the National Institutes of Health, or the Robert Wood Johnson Foundation.
\end{abstract}




\section{References}

1. US Department of Health and Human Services. [Accessed November 1, 2013] Physical Activity Guidelines for Americans. ODPHP publication no. U0036. 2008. Available at: http:// www.health.gov/paguidelines/

2. Pivarnik JM, Chambliss H, Clapp J III, Dugan S, Hatch M, Lovelady C, et al. Impact of physical activity during pregnancy and postpartum on chronic disease risk. Med Sci Sports Exerc. 2006; 38:989-1006. [PubMed: 16672855]

3. Symons Downs D, Chasan-Taber L, Evenson K, Leiferman J, Yeo S. Physical activity and pregnancy: past and present evidence and future recommendations. Res Q Exerc Sport. 2012; 83:485-502. [PubMed: 23367811]

4. American Congress of Obstetricians and Gynecologists. Exercise during pregnancy and the postpartum period. ACOG Committee opinion no. 267. Obstet Gynecol. 2002; 99:171-3. [PubMed: 11777528]

5. de Salles BF, Simao R, Fleck SJ, Dias I, Kraemer-Aguiar LG, Bouskela E. Effects of resistance training on cytokines. Int J Sports Med. 2010; 31:441-50. [PubMed: 20432196]

6. Carrington B, Sacks G, Regan L. Recurrent miscarriage: pathophysiology and outcome. Curr Opin Obstet Gynecol. 2005; 17:591-7. [PubMed: 16258340]

7. Levens ED, Skarulis MC. Assessing the role of endometrial alteration among obese patients undergoing assisted reproduction. Fertil Steril. 2008; 89:1606-8. [PubMed: 17531230]

8. Alfer J, Muller-Schottle F, Classen-Linke I, von Rango U, Happel L, Beier-Hellwig K, et al. The endometrium as a novel target for leptin: differences in fertility and subfertility. Mol Hum Reprod. 2000; 6:595-601. [PubMed: 10871646]

9. Gonzalez RR, Caballero-Campo P, Jasper M, Mercader A, Devoto L, Pellicer A, et al. Leptin and leptin receptor are expressed in the human endometrium and endometrial leptin secretion is regulated by the human blastocyst. J Clin Endocrinol Metab. 2000; 85:4883-8. [PubMed: 11134157]

10. Green BB, Daling JR, Weiss NS, Liff JM, Koepsell T. Exercise as a risk factor for infertility with ovulatory dysfunction. Am J Public Health. 1986; 76:1432-6. [PubMed: 3777292]

11. Gudmundsdottir SL, Flanders WD, Augestad LB. Physical activity and fertility in women: the North-Trondelag Health Study. Hum Reprod. 2009; 24:3196-204. [PubMed: 19801570]

12. Wise LA, Rothman KJ, Mikkelsen EM, Sorensen HT, Riis AH, Hatch EE. A prospective cohort study of physical activity and time to pregnancy. Fertil Steril. 2012; 97:1136-42. [PubMed: 22425198]

13. Morris SN, Missmer SA, Cramer DW, Powers RD, McShane PM, Hornstein MD. Effects of lifetime exercise on the outcome of in vitro fertilization. Obstet Gynecol. 2006; 108:938-45. [PubMed: 17012457]

14. Ainsworth B, Sternfeld B, Richardson M, Jackson K. Evaluation of the Kaiser Physical Activity Survey in women. Med Sci Sports Exerc. 2000; 32:1327-38. [PubMed: 10912901]

15. Baecke J, Burema J, Frijters J. Obesity in young Dutch adults, I: socio-demographic variables and body mass index. Intl J Obes. 1983; 7:1-12.

16. Evenson K, Chasan-Taber L, Symons Downs D, Pearce E. Review of self-reported physical activity assessments for pregnancy: Summary of the evidence for validity and reliability. Paediatr Perinat Epidemiol. 2012; 26:479-94. [PubMed: 22882792]

17. Schmidt MD, Freedson PS, Pekow P, Roberts D, Sternfeld B, Chasan-Taber L. Validation of the Kaiser Physical Activity Survey in pregnant women. Med Sci Sports Exerc. 2006; 38:42-50. [PubMed: 16394952]

18. Ainsworth BE, Haskell WL, Herrmann SD, Meckes N, Bassett DR Jr, Tudor-Locke C, et al. 2011 Compendium of physical activities: a second update of codes and MET values. Med Sci Sports Exerc. 2011; 43:1575-81. [PubMed: 21681120]

19. Choi L, Liu Z, Matthews CE, Buchowski MS. Validation of accelerometer wear and nonwear time classification algorithm. Med Sci Sports Exerc. 2011; 43:357-64. [PubMed: 20581716]

20. Troiano R, Berrigan D, Dodd K, Masse L, Tilert T, McDowell M. Physical activity in the United States measured by accelerometer. Med Sci Sports Exerc. 2008; 40:181-8. [PubMed: 18091006] 
21. Matthews C, Chen K, Freedson P, Buchowski M, Beech B, Pate R, et al. Amount of time spent in sedentary behaviors in the United States, 2003-2004. Am J Epidemiol. 2008; 167:875-81. [PubMed: 18303006]

22. Matthews C. Calibration of accelerometer output for adults. Med Sci Sports Exerc. 2005; 37:S51222. [PubMed: 16294114]

23. Kucuk M, Doymaz F, Urman B. Effect of energy expenditure and physical activity on the outcomes of assisted reproduction treatment. Reprod Biomed Online. 2010; 20:274-9. [PubMed: 20113966]

24. Evenson K, Wen F. National prevalence and correlates of objectively measured physical activity and sedentary behaviors among pregnant women. Prev Med. 2011; 53:39-43. [PubMed: 21575654]

25. Rich-Edwards JW, Spiegelman D, Garland M, Hertzmark E, Hunter DJ, Colditz GA, et al. Physical activity, body mass index, and ovulatory disorder infertility. Epidemiology. 2002; 13:184-90. [PubMed: 11880759]

26. Chavarro JE, Rich-Edwards JW, Rosner BA, Willett WC. Diet and lifestyle in the prevention of ovulatory disorder infertility. Obstet Gynecol. 2007; 110:1050-8. [PubMed: 17978119]

27. Evenson KR, Brouwer RJ, Ostbye T. Changes in physical activity among post-partum overweight and obese women: results from the KAN-DO study. Women Health. 2013; 53:317-34. [PubMed: 23705761]

28. Chasan-Taber L, Schmidt MD, Pekow P, Sternfeld B, Manson J, Markenson G. Correlates of physical activity in pregnancy among Latina women. Matern Child Health J. 2007; 11:353-63. [PubMed: 17345155]

29. Sternfeld B, Ainsworth B, Quesenberry C Jr. Physical activity patterns in a diverse population of women. Prev Med. 1999; 28:313-23. [PubMed: 10072751]

30. Su TJ, Chen YC, Hung YT, Yang YS. Comparative study of daily activities of pregnant and nonpregnant women after in vitro fertilization and embryo transfer. J Formos Med Assoc. 2001; 100:262-8. [PubMed: 11393126]

31. Marshall S, Ramirez E. Reducing sedentary behavior: A new paradigm in physical activity promotion. Am J Lifestyle Med. 2011; 5:518-30.

32. Owen N, Healy G, Matthews C, Dunstan D. Too much sitting: the population health science of sedentary behavior. Exerc Sport Sci Rev. 2010; 38:105-13. [PubMed: 20577058]

33. Bar-Hava I, Kerner R, Yoeli R, Ashkenazi J, Shalev Y, Orvieto R. Immediate ambulation after embryo transfer: a prospective study. Fertil Steril. 2005; 83:594-7. [PubMed: 15749486]

34. Botta G, Grudzinskas G. Is a prolonged bed rest following embryo transfer useful? Hum Reprod. 1997; 12:2489-92. [PubMed: 9436691]

35. Purcell KJ, Schembri M, Telles TL, Fujimoto VY, Cedars MI. Bed rest after embryo transfer: a randomized controlled trial. Fertil Steril. 2007; 87:1322-6. [PubMed: 17362946]

36. Sharif K, Afnan M, Lenton W, Khalaf Y, Ebbiary N, Bilalis D, et al. Do patients need to remain in bed following embryo transfer? The Birmingham experience of 103 in-vitro fertilization cycles with no bed rest following embryo transfer. Hum Reprod. 1995; 10:1427-9. [PubMed: 7593509]

37. Sharif K, Afnan M, Lashen H, Elgendy M, Morgan C, Sinclair L. Is bed rest following embryo transfer necessary? Fertil Steril. 1998; 69:478-81. [PubMed: 9531881]

38. Amarin ZO, Obeidat BR. Bed rest versus free mobilisation following embryo transfer: a prospective randomised study. BJOG. 2004; 111:1273-6. [PubMed: 15521874]

39. Centers for Disease Control and Prevention. Reproductive Technology Fertility Clinic Success Rates Report. Atlanta, GA: US Department of Health and Human Services; 2013. American Society for Reproductive Medicine, Society of Assisted Reproductive Technology; p. 1-561.

40. Masse L, Fuemmeler B, Anderson C, Matthews C, Trost S, Catellier D, et al. Accelerometer data reduction: a comparison of four reduction algorithms on select outcome variables. Med Sci Sports Exerc. 2005; 37:S544-54. [PubMed: 16294117] 
TABLE 1

Description of participants $(\mathrm{n}=121)^{a}$

\begin{tabular}{|c|c|c|c|}
\hline \multirow{3}{*}{ Sociodemographics } & \multicolumn{3}{|c|}{ Participants } \\
\hline & \multirow[t]{2}{*}{$\mathbf{n}$} & \multirow[t]{2}{*}{$\%$} & \multirow[t]{2}{*}{ Missing } \\
\hline & & & \\
\hline \multicolumn{4}{|l|}{ Age (y) } \\
\hline$<35$ & 67 & 55.4 & \\
\hline $35-37$ & 31 & 25.6 & \\
\hline$\geq 38$ & 23 & 19.0 & \\
\hline Race/ethnicity & & & 4 \\
\hline Non-Hispanic Black & 16 & 13.7 & \\
\hline Non-Hispanic White & 82 & 70.1 & \\
\hline Non-Hispanic Asian/Pacific Islander & 15 & 12.8 & \\
\hline Hispanic or Latino & 4 & 3.4 & \\
\hline Education & & & 3 \\
\hline Completed high school or GED & 1 & 0.9 & \\
\hline Some college & 16 & 13.6 & \\
\hline Completed 4-year college degree & 39 & 33.1 & \\
\hline At least some graduate or professional school & 62 & 52.5 & \\
\hline \multicolumn{4}{|l|}{ Health indicators } \\
\hline \multicolumn{4}{|l|}{ Body mass index $b$} \\
\hline Underweight & 6 & 5.0 & \\
\hline Normal weight & 71 & 58.7 & \\
\hline Overweight & 24 & 19.8 & \\
\hline Obese & 20 & 16.5 & \\
\hline Smoke cigarettes & & & 4 \\
\hline Never & 96 & 82.1 & \\
\hline Former & 21 & 18.0 & \\
\hline Current & 0 & 0.0 & \\
\hline \multicolumn{4}{|l|}{ Pregnancy history } \\
\hline \multicolumn{4}{|l|}{ Parity ${ }^{c}$} \\
\hline 0 & 84 & 69.4 & \\
\hline 1 & 29 & 24.0 & \\
\hline$\geq 2$ & 8 & 6.6 & \\
\hline Pregnant in the past & 68 & 58.1 & 4 \\
\hline Previous fresh assisted reproductive technology cycles & 47 & 38.8 & \\
\hline Previous frozen assisted reproductive technology cycles & 20 & 16.5 & \\
\hline \multicolumn{4}{|l|}{ Current IVF } \\
\hline \multicolumn{4}{|l|}{ Embryo quality } \\
\hline Fresh & 100 & 82.6 & \\
\hline Frozen & 21 & 17.4 & \\
\hline Development stage of embryo & & & \\
\hline
\end{tabular}

Fertil Steril. Author manuscript; available in PMC 2015 April 01. 


\begin{tabular}{|lrrr|}
\hline & \multicolumn{3}{c|}{ Participants } \\
Day 2 & n & $\%$ & Missing \\
Day 3 (cleavage) & 10 & 8.3 & \\
Day 5 or 6 (blastocyst) & 81 & 66.9 & \\
Pregnancy outcome & 30 & 24.8 & \\
Positive $\beta$-hCG following IVF & & & \\
Clinical intrauterine gestation & 62 & 51.2 \\
Live birth & 47 & 38.8 \\
\hline
\end{tabular}

Note: GED = general equivalency diploma; IVF = in vitro fertilization. Missing categories also include "don't know" and "refused" for selfreported answers.

${ }^{a}$ Participants had to either complete the physical activity questionnaire or provide compliant accelerometer data.

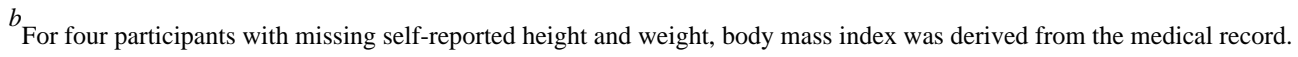

${ }^{c}$ For 22 participants missing parity from the questionnaire, parity was derived from the medical record. 
$\dot{\overrightarrow{0}}$

䓽
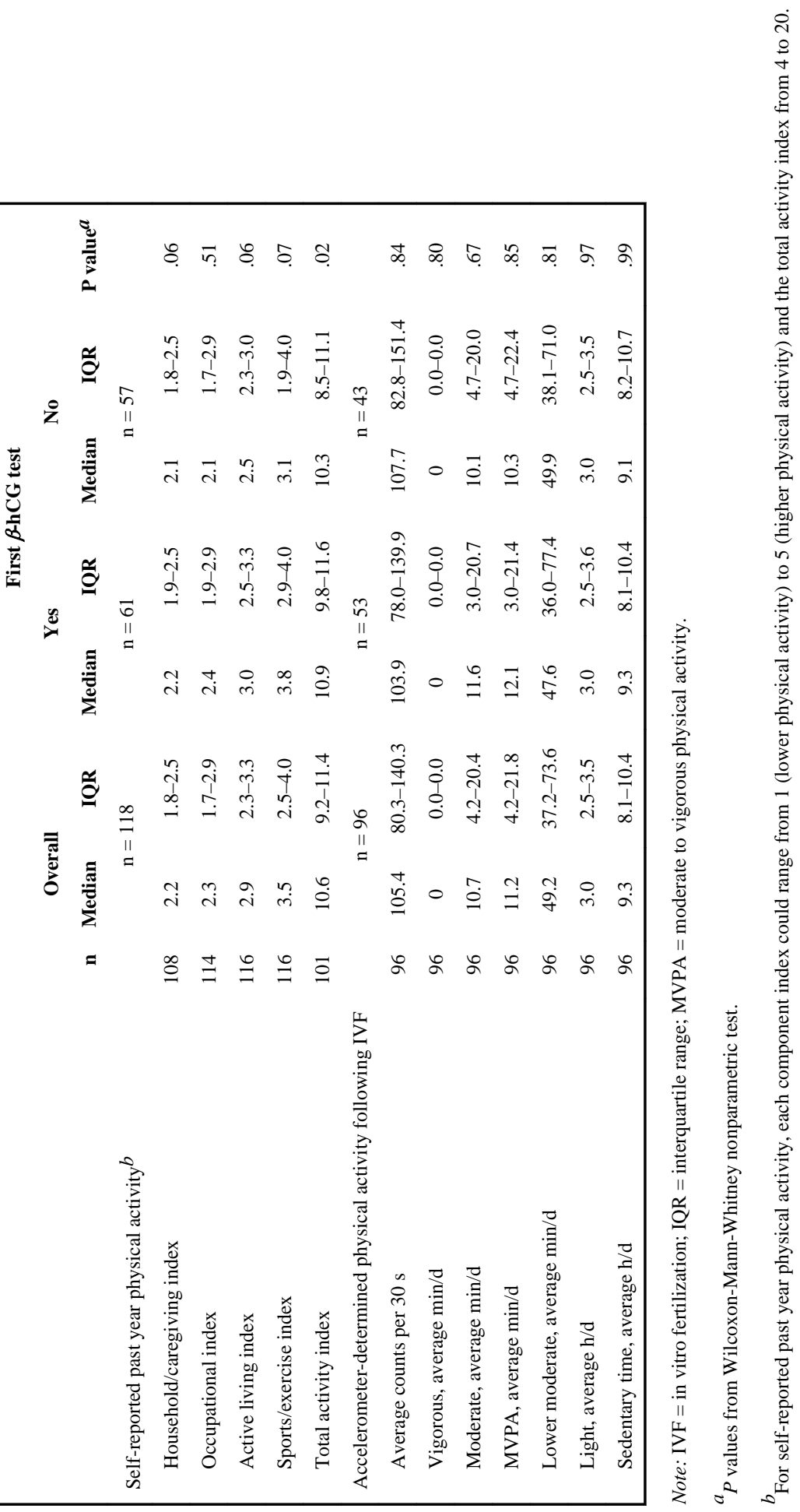

Fertil Steril. Author manuscript; available in PMC 2015 April 01. 


\section{TABLE 3}

Association between self-reported past year physical activity and pregnancy outcomes from adjusted ${ }^{a} \operatorname{logistic}$ regression models.

\begin{tabular}{|c|c|c|c|c|}
\hline & $\mathbf{n}$ & First $\beta$-hCG test, OR $(95 \%$ CI) & $\begin{array}{c}\text { Clinical intrauterine gestation, } \mathrm{OR}(95 \% \\
\text { CI })\end{array}$ & Live birth, OR ( $95 \% \mathrm{CI})$ \\
\hline \multicolumn{5}{|c|}{ Household/caregiving index } \\
\hline Continuously & 108 & $1.21(0.53-2.76)$ & $1.24(0.54-2.86)$ & $1.66(0.68-4.05)$ \\
\hline \multicolumn{5}{|l|}{ Categorically } \\
\hline ymedian (2.2) & 56 & $1.12(0.51-2.42)$ & $1.56(0.70-3.48)$ & $1.57(0.65-3.76)$ \\
\hline$<$ median (referent) & 52 & 1.00 & 1.00 & 1.00 \\
\hline \multicolumn{5}{|l|}{ Occupational index } \\
\hline Continuously & 114 & $1.21(0.76-1.94)$ & $1.29(0.79-2.08)$ & $1.62(0.94-2.79)$ \\
\hline \multicolumn{5}{|l|}{ Categorically } \\
\hline Ymedian (2.3) & 62 & $1.50(0.70-3.22)$ & $1.76(0.80-3.87)$ & $2.61(1.06-6.42)$ \\
\hline$<$ median (referent) & 52 & 1.00 & 1.00 & 1.00 \\
\hline \multicolumn{5}{|l|}{ Active living index } \\
\hline Continuously & 116 & $1.37(0.81-2.32)$ & $1.96(1.09-3.50)$ & $1.40(0.77-2.56)$ \\
\hline \multicolumn{5}{|l|}{ Categorically } \\
\hline ymedian (2.9) & 58 & $2.91(1.36-6.23)$ & $4.30(1.91-9.71)$ & $2.28(0.96-5.39)$ \\
\hline$<$ median (referent) & 58 & 1.00 & 1.00 & 1.00 \\
\hline \multicolumn{5}{|l|}{ Sports/exercise index } \\
\hline Continuously & 116 & $1.40(0.99-1.98)$ & $1.48(1.02-2.15)$ & $1.07(0.73-1.57)$ \\
\hline \multicolumn{5}{|l|}{ Categorically } \\
\hline ymedian (3.5) & 63 & $2.11(1.00-4.45)$ & $1.99(0.92-4.32)$ & $1.09(0.48-2.49)$ \\
\hline$<$ median (referent) & 53 & 1.00 & 1.00 & 1.00 \\
\hline \multicolumn{5}{|l|}{ Total activity index } \\
\hline Continuously & 101 & $1.31(1.02-1.68)$ & $1.52(1.15-2.01)$ & $1.29(0.99-1.68)$ \\
\hline \multicolumn{5}{|l|}{ Categorically } \\
\hline ymedian (10.6) & 51 & $1.77(0.76-4.09)$ & $2.91(1.20-7.04)$ & $2.54(0.99-6.55)$ \\
\hline <median (referent) & 50 & 1.00 & 1.00 & 1.00 \\
\hline
\end{tabular}

Note: For self-reported past year physical activity, each component index could range from 1 (lower physical activity) to 5 (higher physical activity) and the total activity index from 4 to $20 . \mathrm{CI}=$ confidence interval; $\mathrm{OR}=$ odds ratio.

${ }^{a}$ All models were adjusted for age $(<35,35-37,238 \mathrm{y}$ [referent]) and body mass index (under/normal, overweight/obese [referent]). 
TABLE 4

Association between accelerometer-determined physical activity following IVF and pregnancy outcomes from adjusted $^{a}$ logistic regression models $(\mathrm{n}=96)$.

\begin{tabular}{|c|c|c|c|}
\hline & First $\beta$-hCG test, OR (95\% CI) & Clinical intrauterine gestation, OR $(95 \% \mathrm{CI})$ & Live birth, OR (95\% CI) \\
\hline \multicolumn{4}{|c|}{ Average counts per 30 seconds } \\
\hline Continuously & $1.00(0.99-1.01)$ & $1.00(0.99-1.01)$ & $1.00(0.99-1.01)$ \\
\hline \multicolumn{4}{|l|}{ Categorically } \\
\hline$\geq \operatorname{median}(105.4)$ & $0.95(0.42-2.15)$ & $1.08(0.46-2.51)$ & $1.05(0.42-2.61)$ \\
\hline$<$ median (referent) & 1.00 & 1.00 & 1.00 \\
\hline \multicolumn{4}{|c|}{ Vigorous, average minutes/day } \\
\hline Continuously & $0.95(0.84-1.06)$ & $0.98(0.88-1.10)$ & $0.97(0.86-1.10)$ \\
\hline \multicolumn{4}{|l|}{ Categorically } \\
\hline$>0$ & $0.85(0.26-2.76)$ & $0.91(0.27-3.09)$ & $0.74(0.20-2.78)$ \\
\hline 0 (referent) & 1.00 & 1.00 & 1.00 \\
\hline \multicolumn{4}{|c|}{ Moderate, average minutes/day } \\
\hline Continuously & $1.01(0.98-1.04)$ & $1.02(0.99-1.05)$ & $1.03(0.99-1.06)$ \\
\hline \multicolumn{4}{|l|}{ Categorically } \\
\hline$\geq$ median (10.7) & $1.54(0.67-3.54)$ & $1.57(0.67-3.69)$ & $2.19(0.84-5.68)$ \\
\hline$<$ median (referent) & 1.00 & 1.00 & 1.00 \\
\hline \multicolumn{4}{|c|}{ MVPA, average minutes/day } \\
\hline Continuously & $1.00(0.97-1.04)$ & $1.02(0.98-1.05)$ & $1.02(0.99-1.06)$ \\
\hline \multicolumn{4}{|l|}{ Categorically } \\
\hline$\geq$ median (11.2) & $1.28(0.55-2.98)$ & $1.31(0.55-3.11)$ & $2.21(0.84-5.82)$ \\
\hline$<$ median (referent) & 1.00 & 1.00 & 1.00 \\
\hline \multicolumn{4}{|c|}{ Lower moderate, average minutes/day } \\
\hline Continuously & $1.00(0.98-1.01)$ & $1.00(0.99-1.02)$ & $1.00(0.98-1.02)$ \\
\hline \multicolumn{4}{|l|}{ Categorically } \\
\hline$\geq$ median (49.2) & $1.00(0.41-2.43)$ & $1.33(0.53-3.33)$ & $1.75(0.65-4.73)$ \\
\hline$<$ median (referent) & 1.00 & 1.00 & 1.00 \\
\hline \multicolumn{4}{|l|}{ Light, average hours/day } \\
\hline Continuously & $0.99(0.61-1.59)$ & $1.05(0.64-1.70)$ & $0.98(0.58-1.67)$ \\
\hline \multicolumn{4}{|l|}{ Categorically } \\
\hline$\geq \operatorname{median}(3.0)$ & $0.92(0.40-2.12)$ & $1.27(0.54-3.01)$ & $1.63(0.64-4.19)$ \\
\hline$<$ median (referent) & 1.00 & 1.00 & 1.00 \\
\hline \multicolumn{4}{|c|}{ Sedentary time, average hours/day } \\
\hline Continuously & $1.02(0.73-1.41)$ & $0.94(0.67-1.32)$ & $0.98(0.68-1.41)$ \\
\hline \multicolumn{4}{|l|}{ Categorically } \\
\hline zmedian (9.3) & $1.42(0.57-3.57)$ & $1.29(0.50-3.33)$ & $1.42(0.51-4.00)$ \\
\hline$<$ median (referent) & 1.00 & 1.00 & 1.00 \\
\hline
\end{tabular}

Note: Abbreviations as in Tables 1-3.

${ }^{a}$ All models were adjusted for age (<35, 35-37, $>38 \mathrm{y}$ [referent]), BMI (under/normal, overweight/obese [referent]), and average accelerometer wear time. 